\title{
Correction to: The Prevalence of Mental Illness and Substance Abuse Among Rural Latino Adults with Multiple Adverse Childhood Experiences in California
}

\author{
Irán Barrera ${ }^{1}\left[\right.$. Vrinda Sharma ${ }^{2} \cdot$ Yumiko Aratani $^{3}$
}

Published online: 15 September 2018

(c) Springer Science+Business Media, LLC, part of Springer Nature 2018

\section{Correction to: Journal of Immigrant and Minority Health https://doi.org/10.1007/s10903-018-0811-9}

The original version of this article unfortunately published without acknowledgement section. The complete funding information is given below.
The original article can be found online at https://doi.org/10.1007/ s10903-018-0811-9.

\section{Irán Barrera}

IrBarrera@mail.fresnostate.edu

1 Department of Social Work, Fresno State University, 5310

N. Campus Drive M/S PHS 102, Fresno, CA 93740, USA

2 National Center for Children in Poverty, New York City, NY, USA

3 Columbia University Mailman School of Public Health, New York City, NY, USA
Acknowledgements Funded by Kings County Department of Behavioral Health $(\mathrm{KCDBH})$ under a subcontract agreement with Dr. Irán Barrera. Support for this research was also provided in part by the Robert Wood Johnson Foundation. The views expressed here do not necessarily reflect the views of the Foundation and $\mathrm{KCDBH}$. 